Article

\title{
Overview, Evolution and Thematic Analysis of China's Green Consumption Policies: A Quantitative Analysis Based on Policy Texts
}

\author{
Menghua Yang, Hong Chen * ${ }^{\mathbb{C}}$, Ruyin Long * and Congmei Hou \\ School of Economics and Management, China University of Mining and Technology, Xuzhou 221116, China; \\ yangmenghua126@126.com (M.Y.); houcongmei3333@126.com (C.H.) \\ * Correspondence: hongchenxz@163.com (H.C.); longruyin@163.com (R.L.)
}

Received: 10 September 2020; Accepted: 8 October 2020; Published: 13 October 2020

check for updates

\begin{abstract}
Based on the 286 green consumption policy documents issued from 1989 to 2019 at the national level, we analyzed the stage of documents issued, the intergovernmental relationship network of the policy issuing units, and the evolution of the green consumption policy system. The results revealed that: (1) the development of green consumption policies had undergone three stages (i.e., initial stage, preliminary development stage, and deep development stage). For the issuing units, collaborative decision-making by multiple units is a significant phenomenon in the current green consumption policy field; (2) the green consumption policy focus had evolved from placing an initial emphasis on pollution control and clean production to constructing a circular economy and encouraging ecological environmental protection; (3) in respect to the research topic, the results of high-frequency keywords indicated that six clusters were generated, and these included industrial pollution, green product certification and labeling, resource conservation and energy-saving technological development, environmental protection and the energy ecological cycle, the low-carbon economy, and publicity and social participation.
\end{abstract}

Keywords: green consumption policy; pollution control; clean production; circular economy; policy text; quantitative analysis

\section{Introduction}

With the rapid development of the economy, the problems of resource depletion and environmental pollution have become more serious [1]. Although scientific progress and technological innovation have, to some extent, improved resource use [2,3], unsustainable consumption patterns, such as luxury consumption and unreasonable consumption, has led to huge burdens being placed on the carrying capacity of the ecosystem, which has resulted in air pollution, resource depletion, garbage siege, and other environmental problems [4,5]. Consumption, which is one of the important social reproduction links, has a close relationship with resource and environmental problems [6,7]. Therefore, it is critical to guide green consumption patterns, and promote green and sustainable economic and social development, thereby decoupling economic growth from environmental pollution and resource consumption [8,9]. Public participation is an important link in realizing the national strategy for green development. The public is the main practitioner of green consumption. It is essential to promote the public to take the initiative in green consumption, and mobilize the public to play the role of public supervision, thereby actively guiding an environmentally friendly, pollution-free, and healthy green consumption pattern, as well as developing a long-term mechanism in the form of a government-guided market response [10-12].

At present, China has incorporated "green consumption" into its policy agenda, with a view to promote the coordination of green development and sustainable economic growth by 
means of appropriate policy interventions [13]. The report of the 19th National Congress of the Communist Party of China calls for speeding up the establishment of a legal system and policy guidance for green production and consumption, and opposing luxury, waste, and unreasonable consumption [14]. In total, 10 government departments, including the National Development and Reform Commission, jointly issued the "Guiding Opinions on Promoting Green Consumption" policy and proposed 17 measures, which included "encouraging green product consumption, expanding the green consumer market, and promoting green office". These measures were designed to encourage residents to practice green consumption patterns [15]. In the past few years, China has formulated a few regulations and policies related to green consumption from different perspectives and fields. For example, the establishment of a government green purchasing system, the promotion of energy-saving and environmental protection products, and other administrative means; the implementation of energy-saving products to benefit the people project, new energy vehicle subsidies, photovoltaic products subsidies, and other economic means; the promotion of network information platform construction, environmental labeling systems, publicity and education activities, and other information means, has a great guiding significance for the implementation of green consumption. The formation of the green consumption policy system is subject to a process of gradual improvement. China's implementation of green consumption started late, thus a relatively complete green consumption policy system needs to be improved and refined. It is necessary to grasp the current status of the number of green consumption policies, the cooperative relationship of joint issuing units, the high-frequency keywords and their evolution characteristics, and core research topics, so as to explore its future development trends. It is also important to further enhance policy efficiency and thereby improve the policy design and implementation capacity of green consumption management departments.

Research on China's green consumption policy is still in its infancy [16], the research issues are mainly divided into three categories. The first is the basic description of the content and practice of China's green consumption policy. For example, Zhao and Yang (2016) preliminarily analyzed the green consumption policy system based on the product life cycle [17]. The second is to compare and learn from the beneficial experience of other countries' green consumption policies practices. For example, Cao et al. (2020) discussed the enlightenment of Japan's experience in promoting sustainable consumption on China [18]. The third is about the evaluation of green consumption policies, pointing out how to improve the policy system. For example, Yue (2018) explored the establishment and improvement of green consumption policy systems [19]. Generally speaking, there are few academic achievements in the research on green consumption policy, which is limited to a rough discussion and subjective interpretation of policies. No research has been carried out on quantitative content combing and there has been no overall interpretation of China's green consumption policy system. In addition, evaluations of such policies lack objectivity and a scientific approach. As policy research moves towards quantification and objectification, studies which utilize policy content analysis, the bibliometric method, and the quantitative analysis of policy text based on statistics are gradually emerging [20-23]. The quantitative analysis of policy texts permits researchers to obtain objective, reproducible, and verifiable results, and this method facilitates the scientific identification of characteristics that emerge from policy themes at each developmental stage. Quantitative analysis allows researchers to gain a clear understanding of the policy evolution rule from a macro level, and offers greater insight into trends in policy development, which can effectively compensate for the shortcomings of traditional qualitative research [24].

This study provides a vertical and horizontal interpretation of the green consumption policy system and focuses on both its historical and spatial dimensions. By carrying out a comprehensive overview of the policy itself, we can firstly grasp the current status of the publication as a whole. Secondly, we can clarify the cooperative relationship of the main issuing units. Thirdly, we can explore the high-frequency keywords of green consumption policy text, and research the evolution characteristics of the high-frequency keywords in the historical dimension to research its future 
development trends. Finally, we can explore the core research topics of the green consumption policy. Using quantitative research methods, such as co-word analysis and cluster analysis, this study draws conclusions by referring to normative policy research, and thereby avoids the subjectivity of policy analysis as much as possible. These analyses help to explain the future direction of green consumption policies. At a theoretical level, the quantitative research method that is adopted in this paper overcomes the shortcomings of traditional qualitative research, which is too subjective. At a practical level, this study aims to offer guidance for the construction of a green consumption policy system that is in line with China's national conditions, and hopes to promote, to some extent, the coordination of China's economic growth as well as its ecological and environmental protection.

\section{Data Collection and Research Design}

\subsection{Data Collection and Processing}

In this study, the data related to green consumption policies were sourced from the Chinese law retrieval system, the central people's government policy network of the People's Republic of China, the Chinese environmental protection database, and the magic weapon of Peking University. The selection of policy text followed the principles of authoritativeness, openness, and relevance. During the process of the policy text search, we first used the magic weapon of Peking University to carry out a search by inputting the key word "green consumption". The policy literature involves laws, administrative regulations, departmental rules, and normative policy documents issued by China's national legislature, central government, and its main constituent departments. Based on the 304 policy texts from the central government that we found, which covered the period from 1989 to 2019, a second search was conducted on the policy websites of the Central People's Government of the People's Republic of China, the China Environmental Protection Database, and the official government, where 310 policy texts were then found. Excluding policy texts which were of little or no relevance to green consumption, a total of 286 policy texts were finally selected as the sample data for use in this study.

\subsection{Research Method}

This study mainly used word frequency analysis, co-word analysis, and cluster analysis to examine green consumption policy texts. Word frequency analysis is a measurement method that uses the frequency of keywords or subject words which can reveal or express the core content of a document in a research field to determine research hotspots and development trends in the field. This method can count the frequency of keywords that reveal the core content of the literature. When a keyword appears repeatedly in the field, the word can reflect the research focus and hot spots in this field. In this study, the word frequency analysis software ROSTCM 6 was used to perform keyword statistical analysis on the collected and organized policy text content, and the core content and focus of the policy text were analyzed according to the word frequency. On the basis of determining the high-frequency keywords in the text of green consumption policy, through the analysis of co-word and cluster analysis, we found the subject words with high a degree of attention and their potential relationship, and then explored the era evolution of policy focus. Co-word analysis takes keywords in the literature as the research object and counts the frequency of the occurrence of two keywords in the same literature. The stronger the co-word strength, the closer the association between the two words. In this research, keywords that featured in the policy documents which had a high frequency of occurrence were identified by carrying out word frequency statistics, and the co-word matrix of high-frequency keywords was constructed to conduct the keyword clustering analysis. 


\section{Results}

\subsection{Analysis of Policy Issuing Time and Units}

\subsubsection{Policy Issuing Time}

At present, the national policy system to promote green consumption covers five aspects, i.e., laws and regulations, policy documents, systems, technical standards, and promotion projects. The data of the downloaded policy text has been recorded since 1989. Based on the 286 selected policy texts, this study carried out a statistical analysis on the number of policies, document issuing departments, and other content, and determined the current status and developmental trend of green consumption policies as a whole. Figure 1 shows the number of policy texts issued and the cumulative number of Chinese green consumption policies (data as of 31 December 2019).

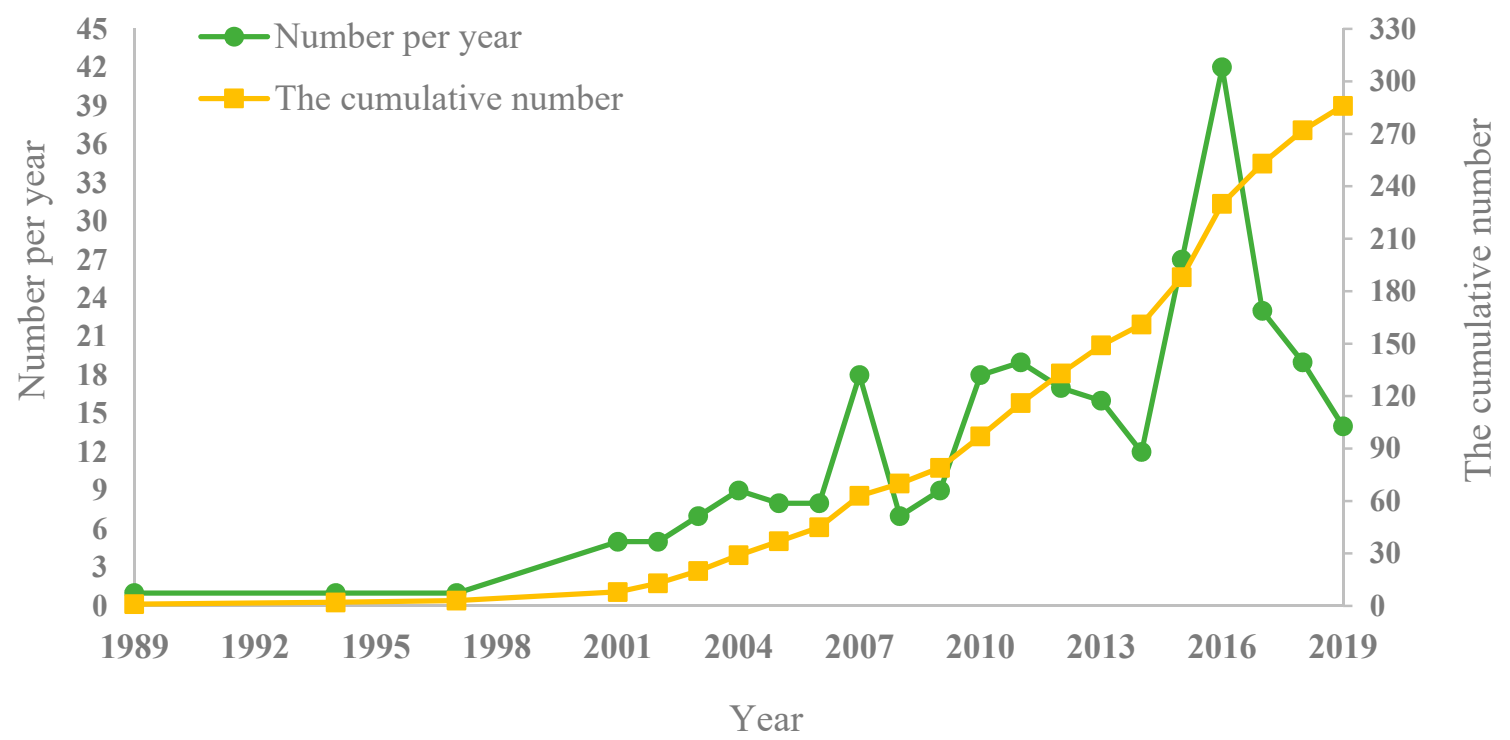

Figure 1. Number of green consumption policies.

According to the annual number curve of green consumption policies, the data shows an overall upward trend, which indicates that an initial stage occurred from 1989 to 2006. Specifically, before 2007, the growth rate of the number of policies in each year was relatively stable, while after 2007, the growth rate increased significantly, among which the growth rate was the largest in 2005-2007 and 2009-2011, and there were two peak growth rates in 2007 and 2016. Based on the key events of China's green consumption and the distribution of green consumption policies, the evolution stages of green consumption policies were divided and the number of policies in each stage was counted. It has roughly gone through the initial stage of 1989-2006, the initial development stage of 2007-2015, and the deep development stage of 2016-2019.

During the initial stage (1989-2006), the number of published policies were in a phase of germination and growth, such that the number of policies rose from eight before 2002 to 45 in 2006 , and this number has developed rapidly in the past 10 years. In 2006, the State Environmental Protection Administration promulgated China's first government green procurement list, which was a key policy breakthrough for China to establish sustainable consumption and promote the construction of an environmentally friendly society. During the preliminary development stage (2007-2015), the number of green consumption policy texts increased significantly. In about 2015, the State Council and relevant departments issued a large number of normative documents and specific system implementation plans to promote green consumption from a top-level design perspective, and to play an explicit, preventive, and corrective role in specific green consumption behavior. During the deep development stage (2016-2019), more than 12 policies were published each year. 
In 2016, 10 departments, including the National Development and Reform Commission, jointly issued guidance on promoting green consumption [15], and made comprehensive efforts to encourage green consumption, which meant that China's green consumption policy system had entered a stage of in-depth development. By 31 December 2019, a total of 286 policies on green consumption were issued.

\subsubsection{Analysis of Policy Issuing Units and Intergovernmental Relations}

Figure 2 lists the top 10 government departments which issued a large number of green consumption policies. From the perspective of departments, the State Council was identified as the department that had issued the highest number of green consumption policies $(N=51)$, and the National Development and Reform Commission was associated with the highest number of joint publications $(\mathrm{N}=40)$. It is evident that the leading departments of national green consumption policy-making include the CPC Central Committee and the State Council, and the main participating departments are the National Development and Reform Commission, the Ministry of Commerce, and the Ministry of Industry and Information Technology.

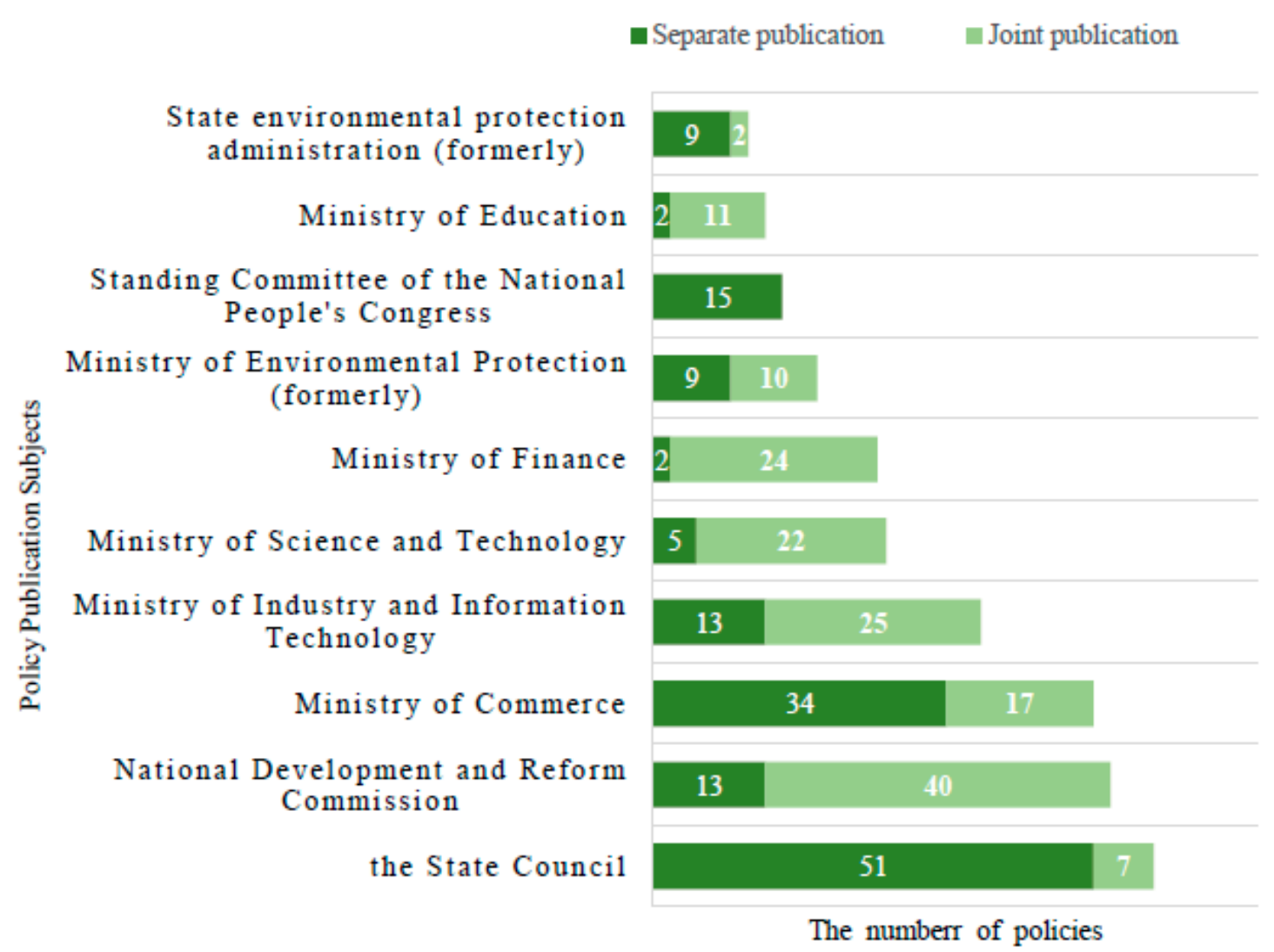

Figure 2. Policy issuing units of green consumption and the corresponding number of issuance.

According to the statistics related to green consumption policies, since 1989 (see Table 1), 75 green consumption policies have been published. Among them, 22 joint publication policies were issued by the two departments, accounting for $29.3 \%$ of the total number of joint publication policies; 41 joint publication articles were issued by the three departments, representing $54.67 \%$ of the total number of joint publication policies. The data show that joint publication is a common phenomenon in the field of green consumption policy. A large number of joint publications also provide research regarding necessary data for network analysis. With the introduction of the concept of governance and the development of interdisciplinary research, an increasing number of scholars are paying attention to the theory of collaborative governance and holistic governance. As shown in Table 1, the number of green consumption policies issued jointly, the number of departments issued jointly, and the proportion of 
policies issued jointly are all high, indicating that collaborative decision-making by multiple units is a significant phenomenon in the current green consumption policy field.

Table 1. Number of joint issuing units and corresponding policies.

\begin{tabular}{cccccccc}
\hline Joint Issuing Units & $\mathbf{2}$ & $\mathbf{3}$ & $\mathbf{4}$ & $\mathbf{7}$ & $\mathbf{8}$ & $\mathbf{1 0}$ & $\mathbf{1 4}$ \\
\hline Number of policies & 22 & 41 & 6 & 2 & 2 & 1 & 1 \\
Percentage & $29.33 \%$ & $54.67 \%$ & $8.00 \%$ & $2.67 \%$ & $2.67 \%$ & $1.33 \%$ & $1.33 \%$ \\
\hline
\end{tabular}

In this paper, the joint issuing behavior of government departments was utilized as the observation index, and the coauthored network analysis was adopted as the research method to study the inter-government relations of the subjects. Intergovernmental relationships refer to the cooperative relations between government departments [25]. This study focused on the joint writing of policy documents (issuing unit $\geq 2$ ), which belongs to the category of intergovernmental cooperative relations. The coauthored network analysis method in bibliometrics was used for reference purposes, and the statistical method involved the frequency of policy citations to identify the cross-sector cooperative relations of green consumption policy. First of all, we extracted the policy issuing units from 286 policy samples, and counted the number of times that each publishing unit issued joint publications with other publishing units, i.e., we counted the number of times that the publishing units cooperated with each other by issuing policies in pairs, and this process formed a co-occurrence matrix. Second, we used UCINET software to analyze the co-occurrence matrix, and Netdraw software to graphically express the relationship between government departments and to draw the cooperation network diagram of government departments (as shown in Figure 3). Among them, the "node" in the network graph represents the unit of policy issuance, the size of the node represents the frequency of issuance, the line segment between the nodes represents the relationship between policy units, the thickness of the line segment indicates the close degree of cooperation between the two policy units, and the node with a high degree of centrality is located in the core of the network.

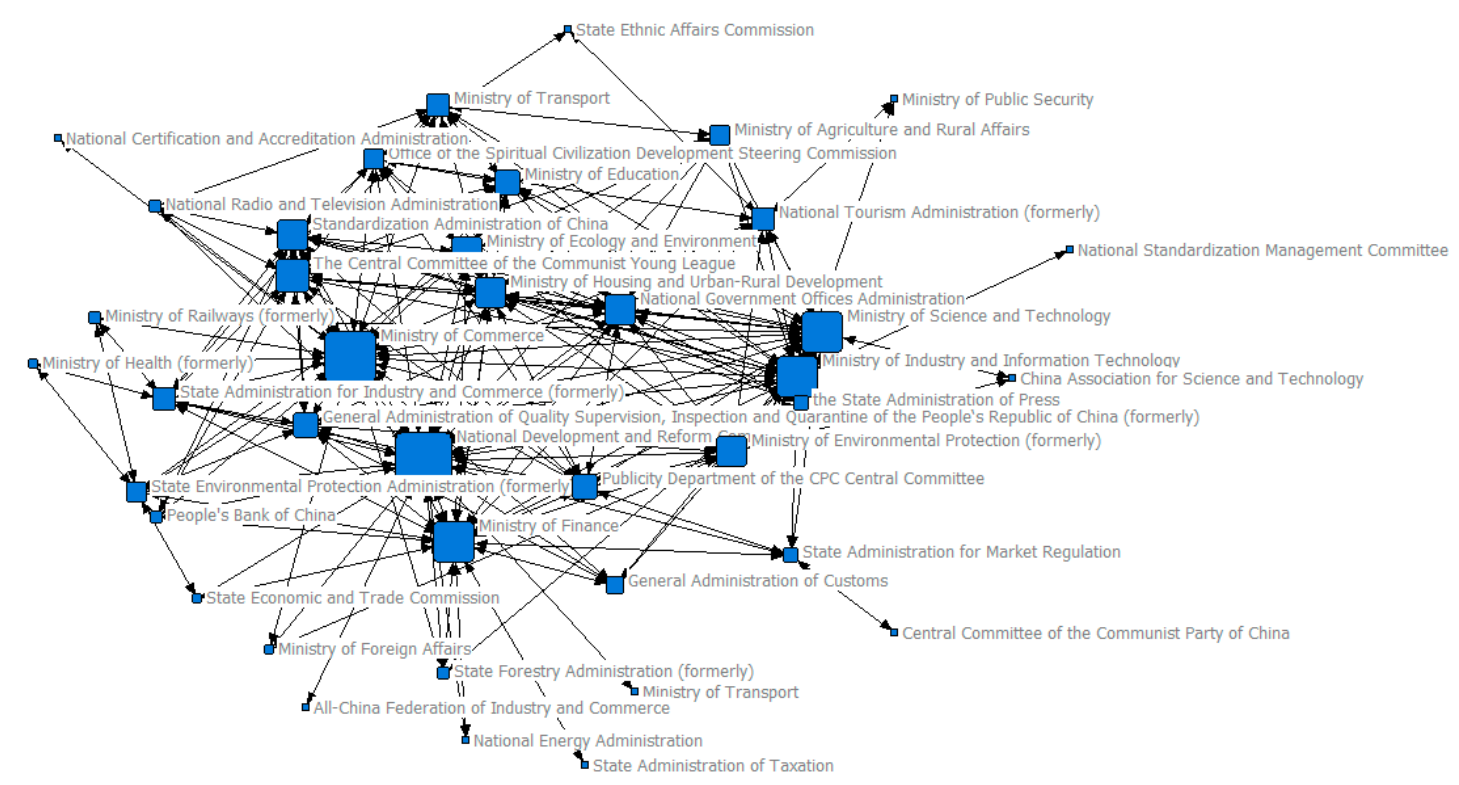

Figure 3. Network diagram of inter-governmental relations of the issuing units.

From the thickness of the line segment, it is evident that the relationship between the National Development and Reform Commission, the Ministry of Science and Technology, the Ministry of Commerce, the Ministry of Ecological Environment, and the Ministry of Finance is relatively close, indicating that the degree of cooperation between them is relatively high, being followed by cooperation 
of the other main issuers. The figure also shows that the All-China Federation of Industry and Commerce, the State Administration of Taxation, the Central Committee of the Communist Party of China, and other departments are located at the edge of the network, indicating that they lack links with other subjects in the inter-governmental network. This suggests that they are basically not connected with other subjects. The relationship between policy subjects is expressed in a graphical way, presenting a map of systematic inter-governmental relationships.

\subsection{Policy Area Division and Structure Analysis}

\subsubsection{Policy Issuing Time}

Drawing on bibliometric research and analysis methods for keywords, this article uses word frequency analysis software ROSTCM 6 to perform keyword statistical analysis on the collected and collated green consumption policy text content. ROSTCM 6 is a content mining system software that performs word frequency statistics, clustering, sentiment analysis, semantic network, and social network analysis for webpages, blogs, microblogs, and other network information sources to realize content mining, text analysis, etc. General conclusions can be drawn from it through quantitative analysis combined with qualitative analysis [26]. This research uses ROSTCM 6 software to perform automatic word segmentation and word frequency analysis to obtain high-frequency keywords in the text of green consumption policy. Through the software's built-in word segmentation filtering function, words that are not strongly related to the research topic were filtered out. Words such as "unit" and "organization", which were not valuable for the research, were deleted. Finally, they were sorted according to the frequency of theme words and the top 30 high-frequency words identified are shown in Table 2.

The statistical results identified high-frequency keywords, which included "green", "environment", "construction", "energy conservation", and "resources", etc. According to the word frequency analysis of the core content and the key points of the policy text, it can be inferred that China's green consumption policy text mainly focuses on resource conservation and ecological environmental protection.

\subsubsection{Co-occurrence Analysis of Policy Text Keywords}

Then, for the 30 high-frequency keywords identified above, we counted the number of times that these keywords appeared in the text of the green consumption policy, forming a $30 \times 30$ common word matrix. The correlation matrix was constructed using the Ochiia coefficient method, that is, each number in the co-word matrix was divided by the product of the total occurrence frequency of the two words related to it. The calculation formula is as follows:

$$
O_{i j}=C_{i j} /\left(\sqrt{C_{i}} * \sqrt{C_{j}}\right.
$$

where $C_{i j}$ indicates the number of times that the two words $i$ and $j$ appeared together, $C_{i}$ indicates the number of times that $i$ appeared, similar to $C_{j}$. Using the above formula, we calculated similar data. The larger the value, the closer the corresponding two words, and the higher the similarity.

On the basis of the word frequency analysis, a co-occurrence network diagram was drawn based on the keyword co-occurrence matrix (as shown in Figure 4). The color block area of the keywords in the figure is related to the number of co-occurrences. The larger the color block, the higher the frequency of cocitation. The network connection indicates the relationship between the keywords. The denser the connection, the closer the keywords. 
Table 2. Frequency statistics of Chinese green consumption policy text.

\begin{tabular}{|c|c|c|c|c|c|c|c|c|}
\hline No. & Keyword & Word Frequency & No. & Keyword & Word Frequency & No. & Keyword & Word Frequency \\
\hline 1 & green & 1560 & 11 & ecology & 658 & 21 & service & 374 \\
\hline 2 & develop & 1189 & 12 & technology & 640 & 22 & publicity & 372 \\
\hline 3 & environment & 1184 & 13 & $\begin{array}{l}\text { environmental } \\
\text { protection }\end{array}$ & 510 & 23 & improve & 366 \\
\hline 4 & construct & 917 & 14 & economy & 500 & 24 & industrial & 363 \\
\hline 5 & energy-saving & 913 & 15 & standard & 496 & 25 & positive & 356 \\
\hline 6 & enterprise & 884 & 16 & protect & 469 & 26 & low carbon & 353 \\
\hline 7 & resource & 741 & 17 & market & 460 & 27 & policy & 346 \\
\hline 8 & consumption & 725 & 18 & manage & 458 & 28 & society & 331 \\
\hline 9 & circulation & 690 & 19 & architecture & 424 & 29 & quality & 327 \\
\hline 10 & energy & 679 & 20 & encourage & 378 & 30 & pollution & 318 \\
\hline
\end{tabular}




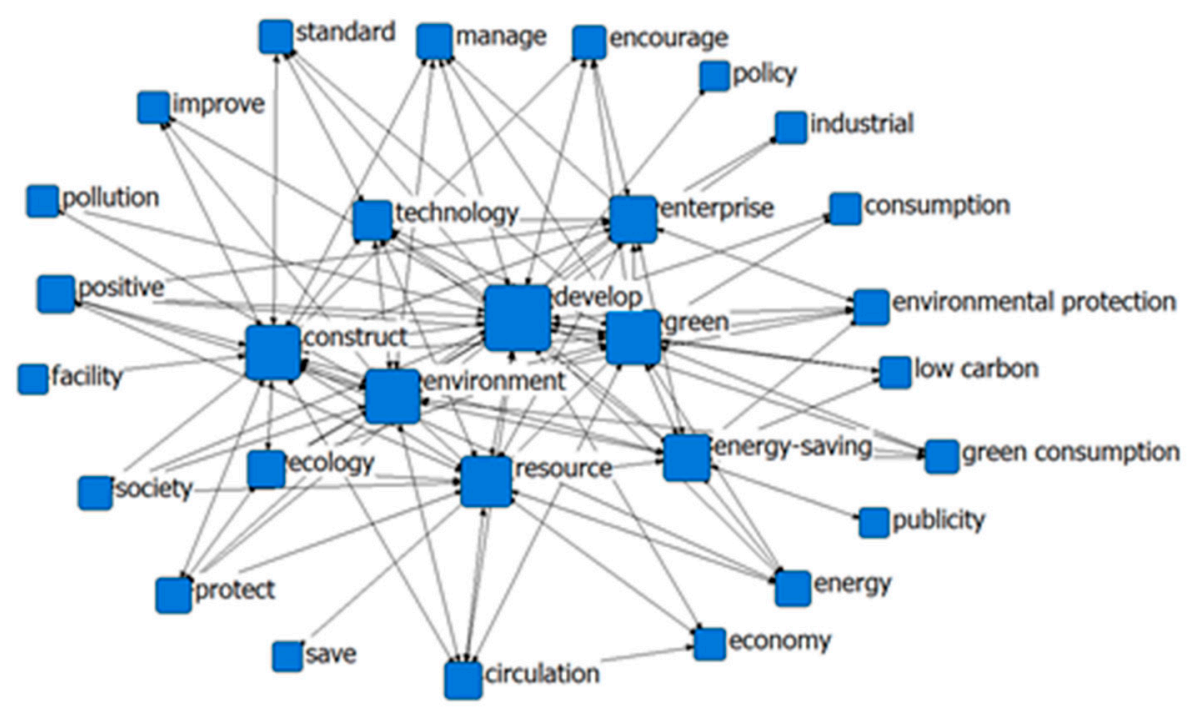

Figure 4. Network diagram of co-occurrence of high-frequency keywords.

Among them, "green", "environment", "development", "construct" and other words were identified as the core hotspots of the green consumption policy text, and they were closely related. Other core words were more distantly related, showed a low frequency of co-occurrence, and appeared in scattered locations. In addition, although the keywords on the edges were less frequent, they cannot be ignored. For example, "society", "enterprise", "publicity", and "participation" also reflect, to some extent, the diversified developmental direction of green consumption policies. The green consumption policy system shows an initial trend of multiplayer participation. In addition to the government, the decision-making system has increased the power of individuals, enterprises, and society, and the window of the policy agenda has been opened.

\subsection{Evolution and Trend of High-Frequency Keywords}

The high-frequency keyword analysis revealed, to some extent, the policy tendency of the green consumption development stage. In order to gain a clearer and more detailed understanding of the specific content of the focus of green consumption policy, and to further explore the development context and evolutionary trend of the green consumption policy system, this study selected the policies from each stage of green consumption, listed the top 15 high-frequency words that were identified with each stage (see Figure 5), and analyzed the theme, role, and developmental trend of the policy based on the frequency of keywords in the policy.

- Initial stage (1989-2006)

During the first stage, the green consumption policy paid greater attention to economic and social development, though ignored the adverse effects of economic and social development on the environment. During these years, the status of environmental protection policies increased, but development was the fundamental key. Many of the issues addressed within the environmental policies referred to the emission control of pollutants and the development and responsibility of enterprises to deal with pollutants. During this stage, the high-frequency keywords, which featured in the green consumption policies included "clean", "pollution", and "energy saving", indicating that the policy system placed an initial focus on the problems associated with environmental pollution and clarified regulations concerning the control, specification, and protection of the pollution problem. At this stage, the policy system emphasized strengthening the development of research and focused on the industrialization of low-carbon or zero-carbon technologies, such as energy conservation, energy efficiency, clean coal, renewable energy, and advanced nuclear energy. At the same time, the keyword "procurement" emerged. The government actively promoted green consumption 
and established a market environment that was conducive to the implementation of cleaner production. This was achieved by developing the labeling system for eco-design products, as well as the environmental certification system, which took advantage of government procurement and other measures.

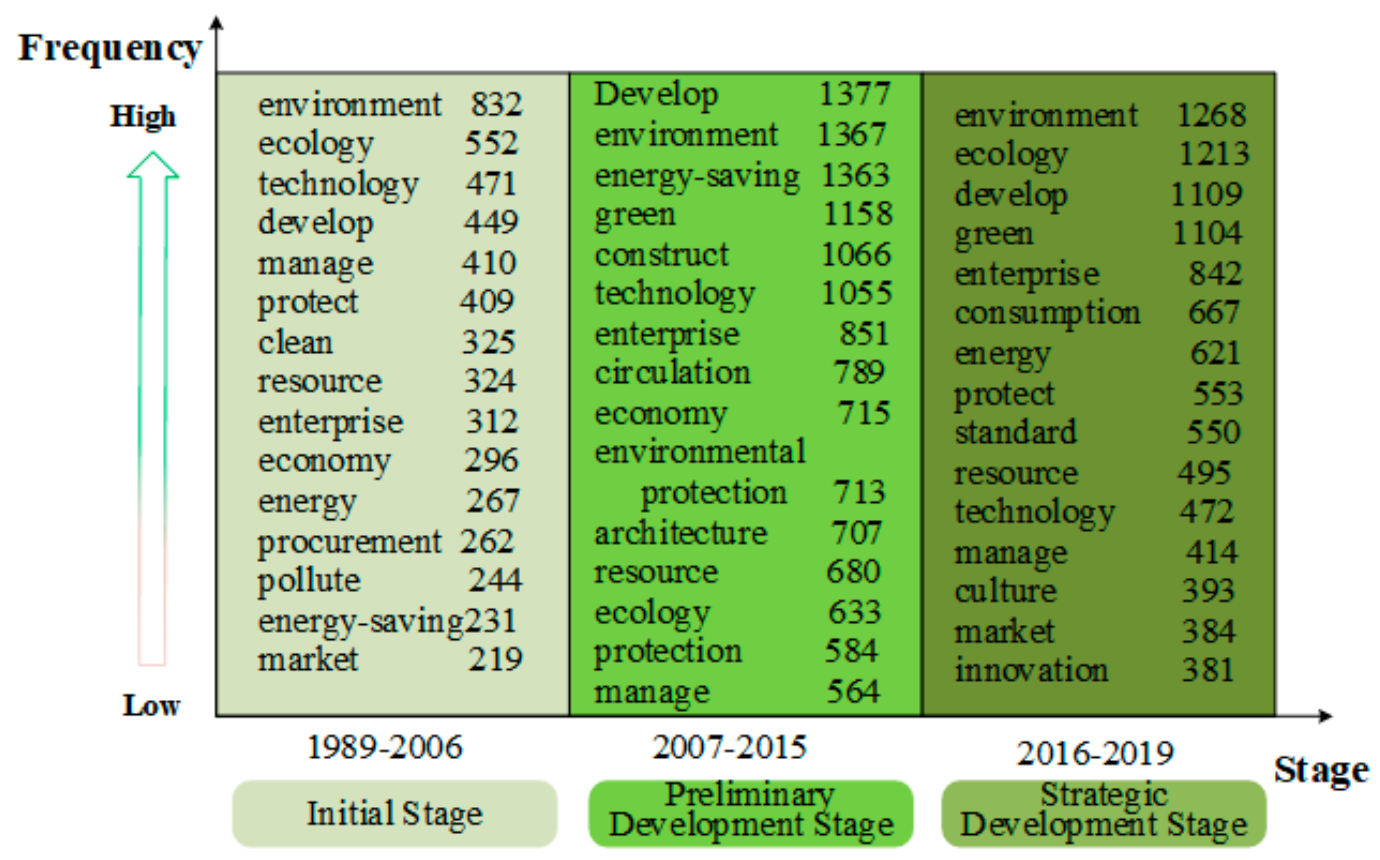

Figure 5. Evolution and trend of green consumption high-frequency keywords.

- Preliminary development stage (2007-2015)

This was a crucial period for China as it deepened the reform of the economic system. This period involved the preliminary development of green consumption policy, but a complete green consumption policy system had not yet been established. Compared with the previous stage, keywords such as "ecology", "green", and "circulation" emerged. After the first stage of efforts, preliminary results were achieved in pollution control. At this stage, increasing attention was paid to the issue of ecological and environmental protection, the coordinated development of the economy and environment was put on the agenda, environmental policies were gradually strengthened, and green consumption policy tools began to appear. It can be seen from the policy texts from this period that the government's work on green consumption development during this time mainly focused on energy conservation, ecological environment, and circular construction. Society exhibited a circular economic development pattern in different domains, such as products, industries, and regions. The green consumption mode was popularized. The resource recycling system, which covered the whole of society, was established, and greater efforts were made in the area of sustainable development. In respect to ecological environment protection, the green consumption policy system was initially established to guide the transformation of production patterns through healthy and economical green consumption patterns.

- $\quad$ Deep development stage (2016-2019)

The third period was the deep development stage of the green consumption policy. The guidance, which was issued by the government to promote green consumption, meant that greater attention was paid to green consumption, but the contradiction and conflict between green consumption and economic development was still prominent. "Energy", "technology", and "innovation" were identified as high-frequency keywords during this period. Green consumption policies continued to focus on promoting green energy and on strengthening its support. An emphasis was placed on improving the subsidy mechanism for wind power and photovoltaic power generation, piloting the issuance and 
voluntary subscription of renewable energy green power certificates nationwide, promoting the consumption and utilization of clean energy, and guiding the whole of society toward green consumption. Furthermore, with the gradual emergence of the effects of the policy implementation and the diversification of policy subjects, the government encouraged the participation of society and enterprises by means of the media, Internet, and other modes. The government vigorously carried out public advertisements for green products, strengthened the interpretation and promotion of green product standards, formed policies for certification and labeling, promoted good examples of green products, disseminated green development concepts, encouraged green lifestyles, and safeguarded the public's right to know, participate, choose, and supervise green consumption.

\subsection{Cluster Analysis of High-Frequency Words in Policy Content}

In order to scientifically cluster high-frequency keywords, this study adopted the optimization clustering analysis function of UCINET software and used the keyword co-occurrence matrix as data for the analysis. Groups were divided by the distance between the policy text and the extracted subject words. The tools-cluster analysis-optimization option was then clicked. The clustering analysis results are shown in Figure 6.

According to the results of the cluster analysis, this study divided the green consumption policy field into six categories which represent the main subdomains of China's green consumption policy, i.e., C1: low-carbon economy, C2: publicity and social participation, C6: industrial pollution, C4: resource conservation and energy-saving technological development, $\mathrm{C} 5$ environmental protection and the energy ecological cycle, C3: green product certification and labeling. Among the hotspots, the cluster " $\mathrm{C} 4$ resource conservation and energy-saving technology development" was the largest as it contained eight keywords, which indicated that the government pays more attention to this type of subject matter and the relevant policies are deeper and broader. The difference between high-frequency keywords within the same topic was relatively small and the connection was strong, while the difference between high-frequency keywords from different topics was relatively large and the connection was weak. By referring to the actual situation of green consumption development, we found that these six hot topics, which were based on cluster analysis, reflect the main content of green consumption policy.

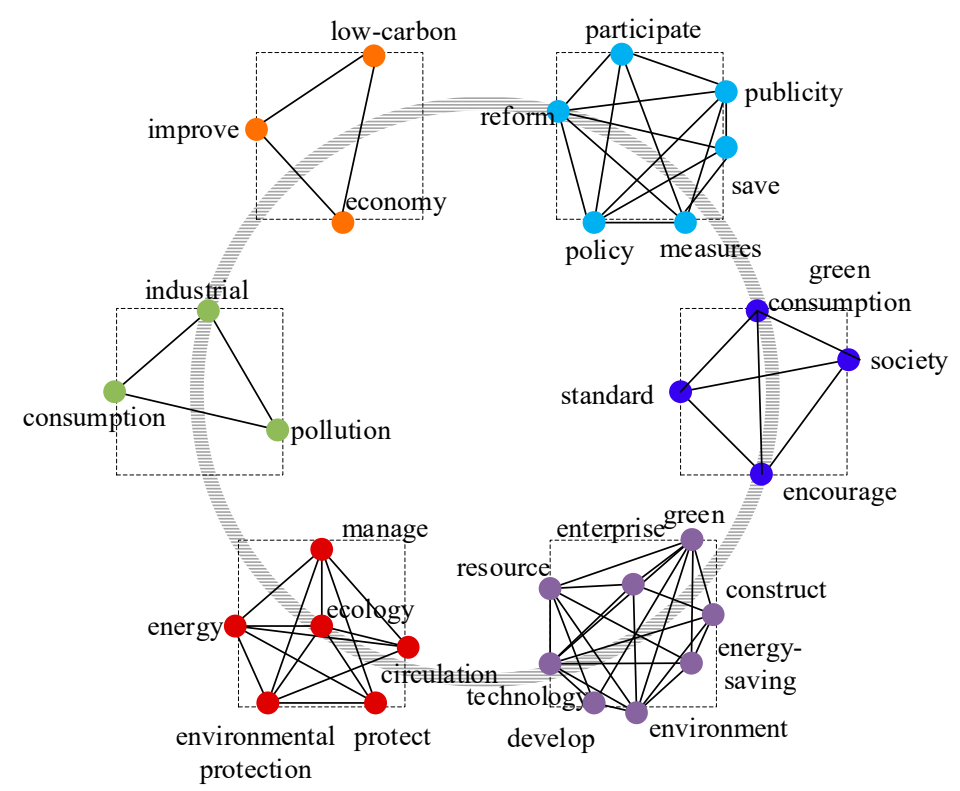

Figure 6. Clustering results of high-frequency keywords. 


\section{Discussion}

By carrying out a quantitative analysis of the green consumption policy text, this study found that China's green consumption policy showed different characteristics during each stage of its evolution and development, but a certain logic was followed in the evolutionary process of the policy.

Since the reform and opening up, economic development has been the core task of society in China, and various policies have been implemented in relation to economic construction [27]. This economic-only development pattern led to serious environmental pollution and caused an ecological crisis [28]. Therefore, greater attention has been paid to environmental protection, and China has gradually established a relatively complete legal framework and policy system of environmental governance with the theme of "environmental protection" [29]. In the 1980s and 1990s, coal-based fossil energy consumption increased rapidly [30], and high-carbon emission energy use resulted in substantial environmental pollution. During this period, policies focused on pollution prevention and energy conservation [31]. Therefore, at the beginning of the formation of a green consumption policy system, green consumption issues mainly focused on pollution control, pollution prevention, and clean production [32]. Based on this, the initial green consumption policy was designed. These policy issues are explicit issues for economic and social development, and are accompanied by the current economic development model. They can have an obvious, intuitive, and serious environmental impact, and can arouse the attention of the government and the public so that they may then form part of the government's policy agenda.

In the process of social development, the issue of green consumption policy has undergone a significant transformation. The government began to pay attention to the construction of a circular economy and introduced a series of related policies, which advocated the development of new equipment and products that have a high level of efficiency and encourage energy conservation, advanced environmental protection, and resource recycling [33]. Furthermore, the policies vigorously promote green consumption and encourage the development of energy-saving and environmental protection industries, with a view to achieve sustainable development and build a "resource-saving and environment-friendly" society [34]. The promotion of environmentally friendly products requires the promotion of the innovative development and widespread application of green technologies. Green technology innovation has the characteristics of high investment cost, high risk, uncertainty, etc., and is subsequently difficult to receive returns in the short term. Therefore, its environmental impact is difficult to visualize in the short term, and represents a long-term development issue. At the same time, China has also begun to adopt green consumption policy tools, such as issuing a series of policies to promote environmental protection across the industrial sector, and to encourage the development of a circular economy. In various fields such as clothing, food, housing, transportation, and tourism, the government has accelerated the transformation to a green economy and pushed green production through green consumption, thereby contributing to the greening of the production mode as well as the lifestyle of the whole society [35]. During this period, the number of green consumption policies increased significantly, the scope of policy coverage gradually became broader, and the policy content was more detailed and comprehensive.

When entering the new stage, policy issues highlighted the important role of technological innovation in green consumption policies. Green consumption policies began to focus on promoting green energy. For example, piloting the issuance and voluntary subscription of renewable energy green power certificates nationwide, so as to promote the consumption and utilization of clean energy. The government began to gradually guide the green development of the industry, promote the research and application of new energy, energy-saving, and environmental protection technologies, and reform and innovate advanced technology to achieve the green transformation and upgrading of the industry, thereby promoting social green consumption. By relying on technological innovation, enterprises can achieve green and sustainable development at both the production and consumption side, so as to avoid environmental governance and pollutant discharge, fundamentally reduce the risk of environmental 
pollution, and improve the use of resource efficiency. Such issues are intrinsic to policy development and can affect the green consumption development.

These policy plans can guide China towards establishing a policy system that is centered on green consumption. However, it is a pity that although green consumption has become the consensus among government departments and even the public [13], the current green consumption policy system is still gradually being formed and improved due to the late start. While the government has already introduced some supporting policies for specific industries, such as heavy subsidies for new energy use. Existing research has found that the government has introduced some supporting policies for specific industries, such as heavy subsidies for new energy use, which has provided certain help for the implementation of green consumption. However, the policy synergy has not been fully exerted, and green consumption has not been widely implemented in China [17]. Therefore, it is necessary to re-examine China's existing green consumption policy system. In this study, the quantitative analysis method was performed to scientifically and objectively extract the stage evolution characteristics of green consumption policy theme, grasp the policy development trend, and obtain objective, reproducible, and verifiable research results. In terms of the number of documents issued, the number of green consumption policy publications increased slowly in the initial stage (1989-2006), increased rapidly in the preliminary development stage (2007-2015), and steadily increased in the deep development (2016-2019). In terms of the issuing units of green consumption policy, cooperative publication by multiple units will become a future development trend in the current green consumption policy field. In terms of the high-frequency keywords, green consumption policy topics evolved from pollution control and cleaner production to ecological environment and recycling construction. In the future, energy, technology, and innovation are new research topics, and the joint participation of government, enterprises, and the public in green consumption is the main trend. In terms of the research topics, it is mainly focused on resource conservation and energy-saving technology developments. Therefore, it is necessary to gradually promote the joint publication of documents and coordinate governance by various departments, pay attention to new energy, green technology innovation, and recycling construction, establish a sound green consumption policy system, and build a long-term mechanism of government guidance, market response, and public participation.

\section{Conclusions}

This study conducted an econometric analysis of 286 policies on green consumption. It used text mining methods to describe the overview, evolution, and main topics associated with green consumption policies, clarified the overall situation related to green consumption policies, and looked forward to future policy development.

(1) The analysis of the 286 green consumption policies which were retrieved revealed that: in terms of the number of documents issued, green consumption policies underwent three stages, i.e., initial stage (1989-2006), preliminary development stage (2007-2015), and deep development stage (2016-2019).

(2) The analysis of the main issuing units of green consumption policy indicated that collaborative decision-making by multiple units is a significant phenomenon in the current green consumption policy field. The State Council issued the largest number of green consumption policies. Additionally, the National Development and Reform Commission, the Ministry of Science and Technology, the Ministry of Commerce, the Ministry of Ecological Environment, and the Ministry of Finance have formed core partnerships.

(3) Based on the analysis of the co-occurrence of high-frequency keywords associated with green consumption policy, keywords including "green", "environment", "construction", "energy saving", and "resources" were identified as the core hot words of green consumption policy. From the perspective of the evolution of keywords during the timeline, green consumption policy initially focused on pollution control and clean production, and mainly emphasized "pollution", "clean" and other elements. Thereafter, green consumption policy topics began to evolve towards the ecological 
environment and recycling construction. In recent years, the focus of green consumption policy has shifted toward diversification, and energy, technology, and innovation have become new topics. In the future, public participation will become an important force in green consumption policy system, and the joint participation of the government, enterprises, and the public will be the main trend.

(4) Based on the cluster analysis of high-frequency keywords for green consumption, the results revealed that the high-frequency keywords were aggregated into six clusters, namely, industrial pollution, green product certification and labeling, resource conservation and energy-saving technology development, environmental protection and the energy ecological cycle, the low-carbon economy, and publicity and social participation. These six clusters reflected the different areas in which current green consumption policies were focused, and such areas include the cluster which is concentrated on resource conservation and energy conservation technology development, which covers the most keywords.

Author Contributions: Conceptualization, H.C. and R.L.; formal analysis, M.Y.; funding acquisition, H.C. and R.L.; methodology, M.Y.; software, M.Y. and C.H.; supervision, H.C.; visualization, H.C. and R.L.; writing-original draft, M.Y; writing-review and editing, M.Y, R.L., and C.H. All authors have read and agreed to the published version of the manuscript.

Funding: This research was funded by: the Major Project of the National Social Science Funding of China: 19ZDA107; the Key Project of the National Social Science Funding of China: 18AZD014; the National Natural Science Funding of China: 71673271; the Think Tank of Green Safety Management and Policy Science (2018 "Double First-Class" Initiative Project for Cultural Evolution and Creation of China University of Mining and Technology): 2018WHCC03; the Jiangsu Philosophy and Social Sciences Excellent Innovation Cultivation Team: 2017ZSTD031; the Postgraduate Research and Practice Innovation Program of Jiangsu Province: KYCX20-1858; the Future Scientists Program of China University of Mining and Technology: 2020WLKXJ034.

Conflicts of Interest: The authors declare no conflict of interest.

\section{References}

1. Fay, M.; Hallegatte, S.; Vogt-Schilb, A.; Rozenberg, J.; Narloch, U.; Kerr, T. Decarbonizing Development: Three Steps to a Zero-Carbon Future; The World Bank: Washington, DC, USA, 2015.

2. Li, A.; Su, J.; Jia, C. Study on the coordinated development and consistency model of economic growth and carbon emissions-Mathematical analysis of macro low carbon economy. Chin. J. Man. Sci. 2017, 25, 1-6.

3. Cheng, Z.; Li, L.; Liu, J.; Zhang, H. Research on energy directed technical change in China's industry and its optimization of energy consumption pattern. J. Environ. Manag. 2019, 250, 109471. [CrossRef] [PubMed]

4. Rockström, J.; Steffen, W.; Noone, K.; Persson, Å.; Chapin, F.S.; Lambin, E.F. A safe operating space for humanity. Nature 2009, 461, 472-475. [CrossRef] [PubMed]

5. Chen, S.Y.; Chen, D.K. Air pollution, government regulations and high-quality economic development. Eco. Res. J. 2018, 53, 20-34.

6. Grunert, S.C. Everybody seems Concerned about the Environment: But is this Concern Reflected in (Danish) Consumers' Food Choice; European Advances in Consumer Research: Aarhus, Denmark, 1993.

7. Wang, H.J.; Xia, Y. Analysis of Influencing Factors and Development Paths of Chinese Consumers' Carbon Emissions. Chin. J. Man. Sci. 2017, 8, 1-10.

8. Elkington, J.; Julia, H. The Green Consumer Guide: From Shampoo to Champagne; High-Street Shopping for a Better Environment; Gollancz: London, UK, 1988.

9. Jie, F.; Sheng, G.H.; Gong, S.Y. Research on the influence of reference group on Chinese residents' green purchasing behavior under the background of national environmental co-governance. Chi. Popu. Resour. Environ. 2019, 29, 66-75.

10. Miniero, G.; Codini, A.; Bonera, M.; Corvi, E.; Bertoli, G. Being green: From attitude to actual consumption. Int. J. Consum. Stud. 2014, 38, 521-528. [CrossRef]

11. Ritter, Á.M.; Borchardt, M.; Vaccaro, G.L.; Pereira, G.M.; Almeida, F. Motivations for promoting the consumption of green products in an emerging country: Exploring attitudes of Brazilian consumers. J. Clean Prod. 2015, 106, 507-520. [CrossRef]

12. Zhou, L.J. Green Consumption: An Environmental Friendly and Healthy Approach for Chinese Consumers. Appl. Mech. Mater. 2014, 694, 426-429. [CrossRef] 
13. Peattie, K. Green consumption: Behavior and norms. Annu. Rev. Environ. Resour. 2010, 35, 195-228. [CrossRef]

14. Xinhua News Agency. Xi Jinping Pointed out that to Accelerate the Reform of the Ecological Civilization System and Build a Beautiful China. Available online: http://news.cyol.com/content/2018-02/06/content_ 16934484.htm (accessed on 18 October 2017).

15. National Development and Reform Commission. 2016; Guiding Opinions on Promoting Green Consumption. Available online: http://www.mofcom.gov.cn/article/bh/201604/20160401305077.shtml (accessed on 25 April 2016).

16. Awuni, J.A.; Du, J. Sustainable consumption in Chinese cities: Green purchasing intentions of young adults based on the theory of consumption values. Sustain. Dev. 2016, 24, 124-135. [CrossRef]

17. Zhao, W.Y.; Yang, J.X. A preliminary study of China's green consumption policy system from the perspective of product life cycle. Chi. Pop. Resour. Environ. 2016, 26, 95-98.

18. Cao, D.D.; Liu, Q.Z.; Zhang, X.D.; Zhou, C.H.; Meng, L.B.; Xue, J.H.; Shi, J.J. Enlightenment from Japan's Experience in Promoting Sustainable Consumption. China Environ. Manag. 2020, 12, 66-70.

19. Yue, X.H. Construction and improvement of green consumption legal system. Chin. For. Acad. J. 2018, 4, 44-49.

20. Li, J.; Liu, H.; Yuan, S.C.; Su, J. Reshaping policy textual data analysis with bibliometrics-The origin, migration and method innovation of policy bibliometrics. J. Pub. Manage. 2015, 12, 138-144+159.

21. Bingham, R.; Felbinger, C. Evaluation in Practice: A Methodological Approach; CQ Press: New York, NY, USA, 2002.

22. Xu, Y. Overview, changes and evolution of China's Marine environmental governance policies-An empirical study based on 161 policy texts from 1982 to 2015. Chi. Pop. Resour. Environ. 2018, 28, 165-176.

23. Liu, Y.; Ye, X.T.; Yang, F.J.; Tan, L.; Liu, W.J. The conception, types and evolution characteristics of internationalization policies of China's national innovation system. Manag. World 2014, 12, 62-78.

24. Huang, C.; Ren, X.; Zhang, J. Quantitative study of policy literature: A new direction of public policy research. J. Pub. Manag. 2015, 2, 129-159.

25. Huang, C.; Ren, X.; Li, J.; Zhao, P.Q. Responsibilities and interests: A study on the evolution of government-to-government cooperation in China's science and technology innovation policy based on quantitative analysis of policy literature. Manag. World 2015, 12, 68-81.

26. Zhang, W.W.; Xu, X. Review of text mining tools. Books Inf. Work. 2012, 56, 26-31+55.

27. Jiang, F.T.; Li, X.P. Evolution and development of China's industrial policy in the past 40 years of reform and opening-up-also on the transformation of China's industrial policy system. Manage. World 2018, 34, $73-85$.

28. Eluwole, K.K.; Saint Akadiri, S.; Alola, A.A.; Etokakpan, M.U. Does the interaction between growth determinants a drive for global environmental sustainability? Evidence from world top 10 pollutant emissions countries. Sci. Total Environ. 2020, 705, 135972. [PubMed]

29. Haas, P.M.; Keohane, R.O.; Levy, M.A.; Gasser, L. Institutions for the Earth: Sources of Effective International Environmental Protection; Mit Press: Cambridge, UK, 1993.

30. Wang, S.J.; Li, C.F.; Zhou, H.Y. Impact of China's economic growth and energy consumption structure on atmospheric pollutants: Based on a panel threshold model. J. Clean Prod. 2019, 236, 117694. [CrossRef]

31. Nicolae, F.; Roman, I.; Cotorcea, A. Econological model to sustainable development of maritime affairs. J. Environ. Prot. Ecol. 2018, 19, 803-813.

32. Song, Y.; Li, Z.; Yang, T.; Xia, Q. Does the expansion of the joint prevention and control area improve the air quality?-Evidence from China's Jing-Jin-Ji region and surrounding areas. Sci. Total Environ. 2020, $706,136034$.

33. Zhang, G.X.; Zhang, Z.H.; Guan, X.; Fang, M. Are the measures and targets of China's energy conservation and emission reduction policies synergistic and effective? Based on 1052 energy conservation and emission reduction policies. J. Manag. Sci. Chi. 2017, 20, 162-182.

34. Liu, M.Q.; Zhang, L.Y. Construction of China's resource-saving and environment-friendly lifestyle. Open Times 2019, 4, 173-190+8.

35. Shittu, O. Emerging sustainability concerns and policy implications of urban household consumption: A systematic literature review. J. Clean Prod. 2020, 246, 119034. [CrossRef]

(C) 2020 by the authors. Licensee MDPI, Basel, Switzerland. This article is an open access article distributed under the terms and conditions of the Creative Commons Attribution (CC BY) license (http://creativecommons.org/licenses/by/4.0/). 